\title{
A Pedagogia da Alternância presente nos Projetos Político-Pedagógicos das Escolas Famílias Agrícolas do Tocantins
}

\author{
Idemar Vizolli' \\ Helena Quirino Porto Aires ${ }^{1}$ \\ Mylena Gonçalves Barreto ${ }^{1}$
}

\section{Resumo}

Este artigo resulta de um estudo mais amplo e tem como objetivo analisar as perspectivas de Pedagogia da Alternância que orientam os Projetos Político-Pedagógicos das Escolas Famílias Agrícolas (EFAs) de Porto Nacional e "Zé de Deus", de Colinas do Tocantins, e verificar que instrumentos pedagógicos são indicados para o acompanhamento das atividades didático-pedagógicas no processo de efetivação da alternância. A Pedagogia da Alternância acontece em tempos/espaços alternados (escola-comunidade), com instrumentos didático-pedagógicos elaborados a partir da realidade da escola e de seus estudantes. A metodologia utilizada foi a pesquisa bibliográfica, com a abordagem qualitativa. Assim, foram realizados estudos bibliográficos que possibilitaram o aprofundamento do conhecimento acerca da Educação do Campo e da Pedagogia da Alternância, bem como a análise dos Projetos Político-Pedagógicos (PPPs) das EFAs supramencionadas. Os resultados indicam que as perspectivas de Pedagogia da Alternância que orientam os PPPs das respectivas EFAs apresentam características de práticas da Pedagogia da Alternância real ou integrativa, descrita por Silva; que elas utilizam como instrumentos didático-pedagógicos o plano de estudo, a folha de observação, o caderno da realidade, o serão de estudo, visitas e viagens de estudo e o caderno de acompanhamento. Tais instrumentos apresentam, em sua estrutura, elementos que dão suporte à formação integral dos jovens no movimento da alternância. A Pedagogia da Alternância é um processo em permanente construção e reconstrução que se constitui numa importante alternativa de atendimento à escolarização dos povos que vivem no e do campo.

\section{Palavras-chave}

Educação do campo - Escola Família Agrícola - Pedagogia da Alternância - Instrumentos didático-pedagógicos.

1- Universidade Federal do Tocantins, Arraias, TO, Brasil.

Contatos: idemar@mail.uft.edu.br; hequirino.uft@mail.uft.edu.br; mylenabarreto@mail.uft.edu.br.

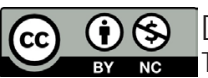




\section{The Pedagogy of Alternation present in the Political- -Pedagogical Projects of the Agricultural Family Schools of Tocantins}

\section{Abstract}

This article results from a broader study and aims to analyze the perspectives of Alternation Pedagogy that guide the Political-Pedagogical Projects of the Agricultural Family Schools (EFAs) of Porto Nacional and "Zé de Deus", from Colinas do Tocantins, and verify which pedagogical instruments are indicated to monitor didactic-pedagogical activities in the process of making alternation effective. The Alternation Pedagogy happens in rotation times / spaces (school-community), with didactic-pedagogical instruments developed from and based on the reality of the school and its students. The methodology used was the bibliographical search plus a qualitative approach. Thus, bibliographical studies were carried out to get a deeper knowledge about Rural Education and Alternation Pedagogy, as well as the analysis of the Political-Pedagogical Projects (PPPS) of the EFAs mentioned above. The results indicate that the perspectives of Alternation Pedagogy that guide the PPPS of the respective EFAs have characteristics of practices of Real or Integrative Alternation Pedagogy described by Silva; that they use the didactic-pedagogical instruments as the study plan, the observation sheet, the notebook of reality, the study period, visits and study trips and the monitoring notebook. These instruments have, in their structure, elements that support the integral formation of young people in the movement of alternation. The Pedagogy of Alternation is a process in permanent construction and reconstruction which is an important alternative in providing schooling for the people who live in and depend on rural areas.

\section{Keywords}

Rural education - Agricultural Family School - Pedagogy of Alternation - Didacticpedagogical instruments.

\section{O lugar de onde falamos}

Este artigo resulta de estudos realizados a partir do Programa Institucional de Bolsa de Iniciação Científica (PIBIC) da Universidade Federal do Tocantins (UFT), campus de Arraias, e integra um projeto mais amplo que visa conhecer a realidade da educação ofertada aos campesinos no Estado do Tocantins. 0 presente estudo tem como objetivo analisar as perspectivas de Pedagogia da Alternância previstas nos Projetos PolíticoPedagógicos da Escola Família Agrícola (EFA) de Porto Nacional e da Escola Municipal 
Família Agrícola “Zé de Deus”, localizada em Colinas do Tocantins, bem como verificar que instrumentos didático-pedagógicos são indicados para o acompanhamento das atividades desenvolvidas no espaço escolar e no tempo da comunidade. Registra-se também que este estudo subsidiou o desenvolvimento da pesquisa de Mestrado em Educação de Aires (2015), que teve como objetivo geral analisar a Pedagogia de Alternância praticada nas EFAs localizadas no Estado do Tocantins.

A metodologia utilizada foi a pesquisa bibliográfica, com a abordagem qualitativa. Assim, para a consecução deste trabalho, foram realizados estudos bibliográficos que possibilitaram o aprofundamento do conhecimento acerca da Educação do Campo, de questões agrárias e da Pedagogia da Alternância. Os encontros de estudos foram organizados e coordenados pelos componentes do Grupo de Estudos e Pesquisa em Educação do Campo (GEPEC) do campus da UFT de Arraias (T0), no ano de 2014. Nos encontros, a relação terra-homem-trabalho-educação foi amplamente discutida, o que permitiu identificarmos aspectos conflitantes nessa relação e a necessidade de uma educação específica a ser ofertada aos povos que vivem no e do campo. Além desses estudos, analisamos os Projetos Político-Pedagógicos (PPPs) das EFAs supramencionadas.

Com o objetivo de identificar as escolas que trabalham com a proposta de Pedagogia da Alternância no Estado do Tocantins, estabeleceu-se contato com as Secretarias Municipais de Educação e com as Diretorias Regionais de Ensino, chegando assim às EFAs de Porto Nacional e "Zé de Deus", de Colinas do Tocantins. A escolha dessas EFAs como locus da pesquisa se deu pelo fato de que elas são protagonistas de experiências em alternância no Estado do Tocantins. Ao contatar as respectivas EFAs, tivemos acesso a seus Projetos Político-Pedagógicos e pudemos coletar informações para a realização das análises previstas neste estudo, o que foi possível a partir dos objetivos da pesquisa e do referencial teórico que trata da Pedagogia da Alternância como proposta educacional para a Educação do e no Campo.

A Pedagogia da Alternância consiste numa proposta educacional que contempla, respeita e valoriza os saberes presentes em contextos socioculturais, considerando a escola, a família e a comunidade como espaços de produção, organização, articulação e difusão de conhecimentos. Na perspectiva da Educação do Campo, a Educação por Alternância acontece nos tempos-espaços escola-família-comunidade, com instrumentos didático-pedagógicos elaborados a partir da realidade da escola e dos estudantes (CALDART et al., 2010; GIMONET, 1983; SILVA, 2012).

A expressão educação do campo [...] constituiu um dos traços marcantes da identidade de um movimento nacional que vem se consolidando na luta por políticas públicas que garantam o direito da população rural a uma educação que seja no e do campo. É um movimento que, conforme destaca Caldart (2004), mais que o direito da população ser educada no lugar onde vive, defende o direito a uma educação pensada desde o seu lugar e com sua participação, vinculada a sua cultura e as suas necessidades humanas e sociais. É, portanto, um olhar para a educação do campo como direito - direito universal, humano e social; mas que apresenta, também, outro desdobramento importante: pensar uma política de educação que se preocupe, também, com o jeito de educar quem é sujeito desse direito, de modo a construir uma qualidade de educação que forme pessoas como sujeitos de direito. (SILVA, 2010, p. 181-182). 
A Lei de Diretrizes e Bases da Educação Nacional (LDB), Lei 9.394/1996, prevê a oferta da educação básica à população do campo. Em seu artigo 28, consta que os sistemas de ensino promoverão as adaptações necessárias às peculiaridades da vida no campo e de cada região, especialmente em relação aos conteúdos curriculares e às metodologias apropriadas, à organização escolar própria e adequada ao calendário, e à natureza do trabalho no campo, ao que é possível implementar propostas pedagógicas distintas daquelas praticadas na grande maioria das escolas de educação básica e mesmo em universidades.

A Pedagogia da Alternância tem se constituído como um diferencial eficaz na articulação de saberes produzidos em diferentes espaços culturais e vem sendo praticada em uma série de situações de educação formal nos diferentes níveis de ensino, sobretudo a partir do segundo segmento do Ensino Fundamental. Ela contém princípios que consideram e valorizam os saberes produzidos nos contextos socioculturais, o que difere substancialmente de muitas propostas educacionais, especialmente porque o processo de ensino e aprendizagem preconiza "o envolvimento e a participação dos pais na educação formal dos filhos e na gestão da escola, embasamento teórico construtivista e adoção de método dialético de ensino" (AZEVEDO, 1998, p. 117).

No Estado do Tocantins, as EFAs de Porto Nacional e de Colinas do Tocantins (educação básica), assim como os campus de Arraias e Tocantinópolis da UFT (Curso de Licenciatura em Educação do Campo na área de Códigos e Linguagem, com habilitação em Artes e Música), desenvolvem cursos inspirados na Pedagogia da Alternância. Assim conseguem atender às demandas de educação de uma parcela organizada da sociedade, particularmente vinculada aos movimentos sociais, o que pode contribuir para a melhoria das condições e da qualidade de vida das pessoas que vivem do e no campo.

Compreender a realidade da Educação do Campo no Estado mais jovem da Federação e analisar Projetos Político-Pedagógicos (PPPs) de cursos inspirados na Pedagogia da Alternância pode contribuir sobremaneira para o processo de efetivação da prática em alternância tanto na educação básica como no ensino superior.

\section{Um breve histórico da implantação da Escola Familia Agrícola de Porto Nacional}

De acordo com o Projeto Pedagógico da Escola Família Agrícola de Porto Nacional, a primeira experiência de Pedagogia da Alternância no Tocantins ocorreu em 1994, ocasião em que essa EFA foi assumida pela Comunidade de Saúde, Desenvolvimento e Educação (COMSAUDE). Trata-se de uma organização não governamental criada em 1969 e que sempre atuou junto aos trabalhadores do campo por meio de suas organizações, como Associações de Agricultores Familiares e Sindicato dos Trabalhadores Rurais. Fato singular em relação à implantação das EFAs em outros estados, normalmente vinculadas à igreja (PORTO NACIONAL, 2015).

A partir das lutas e dos trabalhos da Comunidade de Saúde, Desenvolvimento e Educação (COMSAUDE), em conjunto com as Associações de Agricultores Familiares e com o Sindicato dos Trabalhadores Rurais da região de Porto Nacional, foi possivel a construção do Centro de Tecnologias Alternativas (CTA), com o objetivo de contribuírem na formação 
de agricultores e agricultoras familiares. Esse intento possibilitou o desenvolvimento de diversos cursos: sobre agricultura orgânica, frutos nativos, sementes caboclas, novas tecnologias, apicultura, olericultura, fruticultura, piscicultura, tração animal, políticas agrícolas, entre outros (PORTO NACIONAL, 2015).

No período de 1986 a 1993, os agricultores familiares consideravam as atividades do CTA relevantes para a população, mas ao fazer uma avaliação considerando aspectos sociais, culturais e econômicos, constataram o avanço da agricultura mecanizada e do agronegócio, o que aumentava o êxodo rural, aniquilando cada vez mais a agricultura familiar. Avaliaram que uma das alternativas de enfrentamento residia na necessidade de ampliação da escolaridade de filhos e filhas dos agricultores (PORTO NACIONAL, 2015).

Em contato com o Movimento de Educação Promocional no Espírito Santo (MEPES), ${ }^{2}$ que tem como objetivo promover o homem por meio da melhoria da qualidade de vida no meio rural, membros da COMSAUDE tomaram conhecimento da educação proposta pelas Escolas Famílias Agrícolas. Em 1993, aproveitando a estrutura do CTA e com o objetivo de possibilitar a formação da população do campo do município de Porto Nacional, a COMSAUDE promoveu discussões com o poder público e entidades ligadas ao campo, na perspectiva de implantar a primeira EFA no Estado do Tocantins, cujas atividades educativas tiveram início em 1994 (PORTO NACIONAL, 2015).

Desde a sua implantação, a EFA de Porto Nacional atendeu 3.493 estudantes. No ano de 2015, contava com 389 estudantes matriculados, oriundos de 324 famílias residentes em 93 comunidades camponesas distribuídas em 49 municípios ${ }^{3}$ do Estado do Tocantins. Inspirada na Pedagogia da Alternância, oferta o segundo segmento do Ensino Fundamental (do $6^{\circ}$ ao $9^{\circ}$ ano) e do Ensino Médio (Curso Técnico em Agropecuária Integrado, Técnico em Agroecologia e Magistério de Nível Médio) (PORTO NACIONAL, 2015).

0 Curso Técnico em Agroecologia Integrado ao Ensino Médio acontece nos meses de janeiro e julho e destina-se ao atendimento de agricultores assentados ou reassentados pela reforma agrária, sendo que as despesas com alimentação, transporte, material escolar, pagamento de professores e da equipe administrativa são custeadas pelo INCRA e pelo PRONERA. Os demais cursos acontecem em períodos alternados: em uma semana, os estudantes desenvolvem atividades na EFA (tempo-escola); na outra, desenvolvem atividades nos espaços familiar e comunitário (tempo-comunidade). Trata-se do desenvolvimento de atividades orientadas e acompanhadas por professores e monitores, com anuência dos familiares, que acompanham a realização das ações. Registra-se também que a EFA de Porto Nacional estabelece parcerias por meio de convênios e projetos com instituições públicas, privadas, movimentos sociais, famílias, jovens, organizações não governamentais nacionais e internacionais (PORTO NACIONAL, 2015).

\footnotetext{
2- Mais informações sobre o MEPES estão disponíveis em: <http://www.mepes.org.br>.

3- Porto Nacional, Brejinho de Nazaré, Nova Fátima, Miracema do Tocantins, Rio Sono, Marianópolis, Caseara, Chapada da Natividade, Palmas, Monte do Carmo, Ponte Alta do Tocantins, Pium, Esperantina, Nova Rosalândia, Oliveira de Fátima, Cristalândia, Silvanópolis, Lizarda, Lagoa do Tocantins, Novo Acordo, Dois Irmãos, Araguatins, São Bento, Cachoeirinha, Ananás, Angico, Darcinópolis, Araguaína, Babaçulandia, Nova Olinda, Juarina, Pequizeiro, Araguacema, Tocantínia, Pindorama do Tocantins, Peixe, Figueirópolis, Jaú, São Salvador, Dianópolis, Colinas do Tocantins, Santa Rosa, Ipueiras e Araguacema.
} 
A EFA de Porto Nacional localiza-se no $\mathrm{km} 03$ da rodovia T0-255, possui uma propriedade de aproximadamente 31,55 hectares, com vegetação predominante de cerrado. Conta com 5.392,92 $\mathrm{m}^{2}$ de área construída. As instalações físicas contam com espaços para salas de aula, salas para professores, direção, coordenação financeira, coordenações pedagógicas, secretaria, vídeo, biblioteca, leitura, monitoria, auditório; quadra poliesportiva; laboratórios de informática, ciências, análise de solos; dormitórios, banheiros, lavanderia, cozinha, refeitório; almoxarifado, depósitos para materiais de limpeza, alimentos, ferramentas, insumos agropecuários; abatedouro para aves, garagem, sala de ordenha, chiqueiro, aviário, curral, viveiro. Tal estrutura permite um melhor funcionamento e situações de ensino e aprendizagem aos estudantes, repercutindo na qualidade do processo educacional (PORTO NACIONAL, 2015).

A formação de servidores, famílias, lideranças comunitárias, jovens estudantes e ex-estudantes é articulada com as diversas instituições, como a União Nacional das Escolas Famílias Agrícolas do Brasil (UNEFAB), a Associação Internacional Maisons Familiares Rurales (AIMFR), a Secretaria de Educação de Estado do Tocantins (SEDUC) e o Ministério de Educação (MEC) (PORTO NACIONAL, 2015).

\section{Um breve histórico da implantação da Escola Família Agrícola "Zé de Deus"}

A Escola Família Agrícola "Zé de Deus", de Colinas do Tocantins, iniciou suas atividades no ano de 2000. Para tanto, contou com a participação das entidades ligadas aos trabalhadores rurais da região, como a Cooperativa de Trabalho, Prestação de Serviço, Assistência Técnica e Extensão Rural (COOPTER); a Comissão Pastoral da Terra (CPT); o Movimento dos Trabalhadores Sem Terra (MST); a Faculdade de Ensino Superior de Colinas (FIESC); a Paróquia São Sebastião; e o Sindicato dos Trabalhadores Rurais de Colinas (STR). Além dessas parcerias, contou ainda com o transporte dos estudantes das áreas de assentamento (COLINAS DO TOCANTINS, 2015).

A manutenção da EFA “Zé de Deus” é de responsabilidade da Prefeitura Municipal, mas conta com parcerias: com a Paróquia São Sebastião; com os Missionários Irlandeses, que contribuíram na aquisição do mobiliário e na compra de duas vacas leiteiras; e com a Embaixada Britânica, que financiou a eletrificação rural, a granja de suínos e a criação de aves (COLINAS DO TOCANTINS, 2015).

A EFA “Zé de Deus” oferece o ensino médio (Técnico em Agropecuária Integrado ao Ensino Médio em tempo integral). Atualmente, atende 80 estudantes distribuídos em quatro classes (duas classes de $1^{\text {a }}$ série, uma de $2^{\text {a }}$ e uma de $3^{\text {a)}}$ ), oriundos de 10 comunidades rurais e 12 municípios. ${ }^{4} 0$ curso acontece em períodos alternados de 15 dias na sessão escolar (tempo-escola) e 15 dias na sessão comunidade (tempo-comunidade), totalizando 20 sessões no tempo-escola e 20 no tempo-comunidade por ano letivo. Registra-se que a maioria dos estudantes reside na sede do município de Colinas (COLINAS DO TOCANTINS, 2015).

A EFA “Zé de Deus” localiza-se a $8 \mathrm{~km}$ da cidade de Colinas do Tocantins e conta com uma estrutura física com espaços para direção, secretaria, sala de professores, sala

4- Colinas do Tocantins, Marra do Ouro, Itaporã, Nova Olinda, Pequizeiro, Palmeirante, Couto Magalhães, Bernardo Sayao, Juarina, Itapiratins, Goianorte e Palmas. 
de informática, salas de aula, despensa, refeitório, cozinha, área de serviço e sanitários (COLINAS DO TOCANTINS, 2015), espaços insuficientes para atender, de forma adequada, às demandas de uma educação com qualidade.

\section{O processo educacional nas EFAs}

A Pedagogia da Alternância vem ganhando espaço nas discussões sobre educação. Ela tem sido objeto de estudo de pesquisadores como Bourgeon, Gimonet (1983, 1998 2007) e Silva (2012), entre outros, e tem se mostrado uma alternativa viável à oferta de educação de qualidade aos povos que vivem no e do campo.

De acordo com Nascimento (2007), etimologicamente, a palavra alternância tem suas origens no vocábulo latim alternare, proveniente de alter, que significa outro. Para o autor, a terminologia alternância designa ritmo apropriado, de modo a associar a formação geral com a formação profissional, sob o entendimento de que a primeira estimula a capacidade de o sujeito pensar criticamente, saber lidar com os desafios e/ou problemas existentes na sociedade.

Os estudos de Begnani apontam que a alternância educativa remonta ao início do século XX, supostamente iniciando-se nos Estados Unidos, em cursos superiores, e vem sendo praticada em muitas localidades distribuídas pelo mundo. De acordo com Concagh (1989), a Pedagogia da Alternância nas EFAs foi aprimorada na França em meados de 1930, como uma proposta educacional que objetivava contemplar a realidade dos povos que viviam no campo.

A alternância pedagógica campesina francesa inicia-se com o nome de Maison Familiale Rurale (MFR) ou Casa Familiar Rural (CFR) - no Brasil, Escola Família Agrícola. Assim, a pedagogênese das MFR constitui o início da Pedagogia da Alternância, uma possibilidade de ensino para atender filhos e filhas de camponeses franceses e mantê-los no campo, via oferta de uma educação com qualidade. A partir das avaliações efetuadas pelas MFRs, em 1945, foram propostas mudanças relacionadas à maneira de ensinar, passando-se a utilizar o plano de estudo como principal instrumento pedagógico (GIMONET, 1999).

$\mathrm{Na}$ década seguinte, os Centros Familiares de Formação por Alternância (CEFFAs) se estabeleceram em outros países europeus (Itália, Espanha e Portugal), no continente africano, na América do Sul, no Caribe, na Polinésia, na Ásia e, em seguida, na província de Quebec, no Canadá. Em cada localidade para onde a experiência foi levada, foram feitas adaptações em decorrência das circunstâncias locais (GIMONET, 1999).

\footnotetext{
Em termos de metodologia, elas adaptaram ao ambiente italiano a metodologia francesa. 0 relacionamento com os poderes públicos é grande, portanto certas facilitações são maiores. Os docentes, porém, muitos deles sendo funcionários do Estado, eram menos motivados do que os docentes franceses. É uma experiência que encontrou apoio na igreja, mas nasceu diretamente pela ação de homens políticos: o inverso do que aconteceu na França. (NOSELLA, 2014, p. 57).
} 
Segundo Queiroz (1997), com a atuação do Padre Humberto Pietrogrande ${ }^{5}$ nos movimentos sociais do Espírito Santo, desde o ano de 1965, aliada ao trabalho comunitário com participação de várias forças sociais, foram implantadas as primeiras EFAs no Brasil, com base na experiência italiana. Em virtude da crise econômica e social pela qual passavam os agricultores do sul do Estado do Espírito Santo, na década de 1960, as lideranças do Movimento de Educação Promocional do Espírito Santo (MEPES) assumiram a tarefa de construção das EFAs capixabas.

[...] o processo de implantação das EFAs, no Brasil, teve início no auge da ditadura militar, período em que o campo sofreu um processo de total abandono por parte dos poderes públicos, excluindo a agricultura familiar. As políticas públicas para o campo, naquela época, estavam centradas na grande produção agropecuária, no modelo de agricultura patronal, voltado para monoculturas e o mercado externo, associado à sofisticação tecnológica, conhecida como modernização conservadora. (ARAÚJO, 2005, p. 91).

Como as experiências de alternância foram se ampliando, sentiu-se a necessidade de maior articulação e união das unidades mantedoras na resolução dos problemas nessa proposta de formação. Em uma assembleia geral das EFAs no Brasil, realizada em 1982, foi criada a União Nacional das Escolas Famílias Agrícolas no Brasil (UNEFAB).

Os CEFFAs se organizaram em Associações Regionais das Casas Familiares Rurais (ARCAFAR-SUL, criada em 1989; e ARCAFAR-NORTE/NORDESTE, criada em 1996). De acordo com dados da UNEFAB e das ARCAFAR, existem, atualmente, 264 escolas comunitárias que adotam a proposta da Pedagogia da Alternância em todo o país. Elas atendem mais de 17 mil estudantes. ${ }^{6}$

Escola família ajuda o jovem rural na sua formação humana e técnico-profissional de maneira a torná-lo, dentro das possibilidades, um homem preparado, responsável e dinâmico para o desenvolvimento de sua futura família, de sua propriedade e da sua comunidade. E, se por qualquer motivo ele não encontrar no seu ambiente a oportunidade de formar a sua família e de se integrar numa atividade econômica, que ele seja um homem apto a tomar decisões e escolher sua profissão para o seu bem e o da comunidade a que irá se integrar. (MEPES, 1976, p. 90 apud NASCIMENTO, 2007, p. 40).

Nessa perspectiva, a Pedagogia da Alternância consiste numa proposta educativa de organização do ensino escolar conjugada em diferentes espaços de aprendizagem, que possibilita a formação integral dos estudantes em seus aspectos sociais, intelectuais e culturais (GIMONET, 1999; NASCIMENTO, 2007; TEIXEIRA et al., 2008).

$\overline{5}$ - Fundador do Movimento de Educação Promocional do Espírito Santo (MEPES), em 1969, na cidade de Anchieta (ES). Trabalhou intensamente na promoção integral do homem do campo, foi o grande incentivador da instalação das primeiras Escolas Famílias Agrícolas no Brasil. Exerceu 0 ministério sacerdotal como cooperador e pároco de Anchieta e Alfredo Chaves (ES). Faleceu em 5 de agosto de 2015.

6- Informação disponível em: <http://agenciabrasil.ebc.com.br/educacao/noticia/2014-11/seminario-debate-situacao-de-escolas-comunitariascom-pedagogia-de>. 
A Pedagogia da Alternância baseia-se na "alternância de tempo e de local de formação, ou seja, de períodos em situação sócio-profissional e em situação escolar" (GIMONET, 1999, p. 44), e acontece em espaços, territórios diferenciados e alternativos.

0 primeiro é o espaço familiar e a comunidade de origem (realidade); em segundo, a escola onde o educando/a partilha os diversos saberes que possui com outros atores/as e reflete-se sobre eles em base científica (reflexão); e, por fim, retorna-se a família e a comunidade a fim de continuar a práxis (prática + teoria) seja na comunidade, na propriedade (atividades técnicas agrícolas) ou na inserção em determinados movimentos sociais. (NASCIMENTO, 2003, p. 1-2).

Assim, essa proposta de ensino se configura como uma possibilidade de valorização dos saberes produzidos pelos povos em interação entre escola-família-comunidade. Para Gimonet (1999, p. 44), Pedagogia da Alternância é "uma outra maneira de aprender, de se formar, associando teoria e prática, ação e reflexão, o empreender e o aprender dentro de um mesmo processo". Assim, a alternância significa "uma maneira de aprender pela vida, partindo da própria vida cotidiana, dos momentos de experiências colocando assim a experiência antes do conceito".

Para Bourgeon (1979 apud QUEIROZ, 2004, p. 94), a alternância é uma "compenetração efetiva de meios de vida sócio-profissional e escolar em uma unidade de tempos informativos". Em tal perspectiva, esses espaços formativos contribuem para uma formação contextualizada, que é um dos elementos essenciais da Pedagogia da Alternância.

Nesses termos, a Pedagogia da Alternância se caracteriza por possuir uma metodologia própria que alterna a formação entre momentos no ambiente escolar e momentos no ambiente familiar-comunitário. Assim, a ideia de alternância tem um sentido de estratégia de escolarização que, segundo Silva (2012), possibilita aos estudantes conjugar sua formação escolar com os afazeres do produtivo familiar, sem perder o vínculo com sua família e com seu meio, fator imprescindível ao processo de alternância.

Na alternância, o tempo-escola se desenvolve no espaço interno da instituição, com aulas, atividades de estudo, reflexões, leituras e oficinas, atividades culturais e esportivas. 0 tempo-família-comunidade se desenvolve em espaços externos à unidade escolar, abrangendo trabalhos de pesquisa, leituras e atividades práticas de escrita acompanhadas, orientadas e avaliadas pelo educador-monitor. A alternância possibilita partir da prática para a teoria, o que necessariamente considera as experiências concretas das pessoas.

Existem EFAs em que o estudante permanece um período na escola (tempo-escola) e outro junto com a família (tempo-comunidade). Um dos elementos cruciais da proposta da Pedagogia da Alternância é a participação familiar do processo de ensino e aprendizagem:

Associação e participação das famílias constituem, assim, componentes indissociáveis e fundamentais na expressão das realidades, necessidades e desafios no contexto socioeconômico, cultural e político da escola, e na articulação com as organizações, entidades e movimentos presentes na realidade local, orientados para a construção de projeto não apenas para o futuro dos alunos, mas para também para a região. (SILVA, 2012, p. 182). 
Nesses termos, há a necessidade de uma relação estreita entre família e escola a fim de que realmente aconteça a alternância. É nesse contexto mútuo que se constrói a formação integral do estudante, uma formação que atenda aos anseios das comunidades. Para Gimonet (1998), uma verdadeira alternância ocorre na articulação entre escola-família-comunidade, não se resumindo à abertura da escola de forma descontextualizada, ensinando para o mundo exterior, sem considerar o contexto dos sujeitos envolvidos. É sob esse aspecto que se insere o verdadeiro processo pedagógico para o qual se propõe a formação por alternância.

Assim, a alternância se constitui numa proposta educacional como possibilidade de resposta à problemática da Educação do Campo. Ela tornou-se, com o passar dos anos, uma alternativa viável e promissora para filhos e filhas dos sujeitos que vivem no e do campo. Possibilita aos sujeitos envolvidos no processo de ensino e aprendizagem uma interação com o contexto escolar, familiar e da comunidade, proporcionando saberes diversos que podem contribuir na formação integral dos sujeitos (SILVA, 2012).

Todavia, como bem destacado por Gimonet (2007) e Silva (2012), a distância entre a teoria e a prática da alternância ainda é bastante comum nas escolas. Encontramos diversas instituições que anunciam em seus documentos a alternância e na prática não a fazem: há apenas uma alternância de tempos e de espaços, e não de ações num processo de construção do conhecimento via ação-reflexão-ação, o que é possível por meio do diálogo com vistas à transformação da realidade em sua dinamicidade.

Girod de l'Ain (1974 apud SILVA, 2012) identificou dois modelos: a alternância externa, que consiste na relação escola-empresa e tem como objetivo desenvolver os saberes escolares com sujeitos que já tenham experiência com o meio profissional; e a alternância interna, que é articulada no meio da formação com a realização de atividades profissionais no período de estudo e não utiliza o trabalho como fator essencial para a formação.

Malglaive (1979 apud SILVA, 2012) definiu três tipos de alternâncias que são praticadas: a falsa alternância, que consiste em espaços vazios durante os períodos de alternância e em falta de conexão entre a formação acadêmica e as atividades práticas; a alternância aproximativa, a qual possui instrumentos pedagógicos que associam os tempos formativos limitados à observação e à análise, sem oferecer meios de atuação na realidade; e a alternância real, que busca a formação teórica e prática global, permitindo ao estudante a construção do seu próprio projeto pedagógico que possibilita a atuação crítica sobre a realidade.

Autores como Gimonet (1983), Bachelard e Bourgeon retomam as classificações de alternância propostas por Malglaive e as readaptam com outras denominações, as quais, segundo Silva (2012), propõem, sucessivamente, tipologias específicas a partir de diferentes critérios: seja de disjunção e divisão entre os dois períodos da alternância ou, ao contrário, de articulação e unidade da formação entre os dois momentos. Dentre eles, destacamos Bourgeon, que define a alternância justapositiva, caracterizada pela sucessão dos tempos ou períodos consagrados ao trabalho e ao estudo, sem que haja uma relação entre eles; a alternância associativa, quando ocorre uma associação entre a formação geral e a profissional, verificando-se, portanto, a existência da relação entre a atividade escolar e a atividade profissional, mas ainda como uma simples adição; e a alternância copulativa, com a compenetração efetiva dos meios de vida socioprofissional e escolar em uma unidade de tempos formativos. 
Em estudos anteriores, Silva $(2000,2010)$ assevera que, embora os autores utilizem termos próprios para definir as diferentes formas de alternância, as tipologias apresentam semelhanças entre si e referem-se à

[...] alternância justapositiva ou falsa alternância - que se caracteriza pela sucessão temporal de períodos consagrados a atividades diferentes em locais diferentes, sem o estabelecimento de nenhuma ligação explícita entre a formação e atividades práticas; à alternância aproximativa ou associativa - que apesar de envolver certo nível de organização didática na vinculação dos dois tempos e espaços da formação, caracteriza-se muito mais por uma simples adição de atividades entre si; e à alternância real ou integrativa, que consiste em efetivo envolvimento do educando em tarefas da atividade produtiva, de maneira a relacionar suas ações à reflexão sobre o porquê e o como das atividades desenvolvidas. Ou seja, uma vinculação efetiva dos tempos e espaços alternados, em uma unidade de tempo formativo, não se tratando de mera sucessão de tempos teóricos e tempos práticos. (SILVA, 2010, p. 186-187, grifos do autor).

Ainda de acordo com Silva (2010, p. 187), o desenvolvimento da alternância

[...] exige a presença de dispositivos pedagógicos, uma organização de atividades, de técnicas e de instrumentos específicos que, por sua vez, estejam em coerência e articulados com o projeto e os princípios da formação e dos sujeitos envolvidos nas experiências educativas. Isto porque, conforme alerta Gimonet (2007), é grande a distância entre o conceito e a prática da alternância proposta.

\section{A Pedagogia da Alternância e os instrumentos pedagógicos nas Escolas Famílias Agrícolas de Porto Nacional e "Zé de Deus"}

A Pedagogia da Alternância da EFA de Porto Nacional inspira-se na Pedagogia da Libertação, de Paulo Freire, que tem como princípio a certeza de que a educação é um ato político, de construção do conhecimento e de criação de uma sociedade mais ética, mais justa, mais humana, mais solidária. Em outras palavras, uma sociedade que luta a favor das classes oprimidas, pela liberdade e pela igualdade, proporcionando uma educação crítica a serviço da transformação social. Nessa perspectiva, busca oferecer uma educação que leve os estudantes a refletirem sobre a realidade do contexto social, político, econômico e cultural; que esteja comprometida com o trabalho e com as lutas cotidianas dos camponeses; que se baseie em uma educação libertadora e emancipadora, com vistas à formação integral dos sujeitos (PORTO NACIONAL, 2015).

Os PPPs das EFAs de Porto Nacional e "Zé de Deus" apresentam objetivos e metas que possibilitam o desenvolvimento das atividades na perspectiva da Pedagogia da Alternância, explicitando o atendimento da população que vive no e do campo, bem como visando à promoção da formação integral dos sujeitos e ao desenvolvimento local. Assim, o processo da Pedagogia da Alternância é articulado por meio dos instrumentos pedagógicos, que são dispositivos de ação que possibilitam ao estudante relacionar-se com a família, com os parceiros da formação, com o conhecimento científico e com o 
meio socioprofissional e cultural de maneira ativa, buscando sua formação integral e sua atuação para o desenvolvimento do meio onde vive.

A Pedagogia da Alternância baseia-se na colaboração e na partilha do poder pedagógico; a alternância diversifica e multiplica os coformadores (pais, responsáveis, tutores, monitores e outros atores que fazem parte do processo de escolarização); e os instrumentos pedagógicos possibilitam a colaboração e a partilha (GIMONET, 2007).

Além de imprescindíveis ao processo de formação, os instrumentos pedagógicos são essenciais para nortear o desenvolvimento das atividades no processo da Pedagogia da Alternância; constituem-se no elo entre os espaços de aprendizagem escolar-familiar-comunitário e são indispensáveis à socialização e à mediação de conhecimentos fundantes dos saberes.

\begin{abstract}
A pedagogia da Alternância é compreendida como um processo formativo de ensino aprendizagem que considera uma diversidade de tempos, espaços e formadores diferentes. A mesma consiste em períodos de formação no centro de Educação Familiar de Formação por Alternância - CEFFA, acompanhado pela equipe de monitores, alternado semanalmente com períodos de formação no meio familiar, profissional e comunitário articulado pelo conjunto de instrumentos pedagógicos. (PORTO NACIONAL, 2015, p. 38).
\end{abstract}

A Pedagogia da Alternância consiste na formação do jovem em diferentes espaços - familiar, comunitário, escolar, institucional, diferentes tempos - sessão escola e sessão família/comunidade/ trabalho - e diferentes formadores - família, profissionais diversos, lideranças comunitárias, técnicos, especialistas, monitores, etc. (COLINAS DO TOCANTINS, 2015, p. 5-6).

Nesse sentido, a concepção de Pedagogia da Alternância proposta nos PPPs das EFAs possibilita aos estudantes uma bagagem cultural, uma relação de respeito à família, o conhecimento da lida do campo, uma relação de convivência harmoniosa, de escuta e de amizades, o que pode favorecer o desenvolvimento de um trabalho mais eficaz no ambiente escolar e no ambiente família-comunidade (QUEIROZ, 2004).

0 exposto nos PPPs das EFAs em relação à Pedagogia da Alternância dá indícios da alternância real ou integrativa de que trata Silva (2010), especialmente porque o processo formativo considera as produções dos sujeitos no tempo-escola e no tempo-comunidade, em que atividades são orientadas por profissionais da educação, com anuência e acompanhamento familiar, cujos processos são registrados em diferentes instrumentos pedagógicos acessíveis aos envolvidos no percurso educativo dos sujeitos.

A dinâmica da Pedagogia da Alternância proposta nos PPPs das EFAs apresenta a articulação da teoria e da prática nos tempos e espaços diferentes para trabalhar a educação por alternância. Gimonet (2007) argumenta que por meio dos instrumentos pedagógicos é possível perceber que tal articulação se fundamenta na colaboração dos envolvidos (estudantes, famílias, professores, comunidade) no processo de ensino e aprendizagem. Por intermédio dos instrumentos pedagógicos, é possível que, a qualquer momento, cada envolvido no processo educacional tenha acesso a informações úteis à avaliação do empenho e do desempenho do estudante, da escola e de seus familiares. 
Os Instrumentos Pedagógicos são os dispositivos de ação que possibilitam a efetivação da Pedagogia da Alternância, permitindo ao estudante, relacionar-se com a família, com os parceiros da formação, com o conhecimento científico e com o meio sócio-profissional e cultural de maneira ativa, buscando sua formação integral e sua atuação para o desenvolvimento do meio. Esses instrumentos têm espaços dentro da estrutura escolar e são utilizados de forma transversal nas disciplinas curriculares. (PORTO NACIONAL, 2015, p. 17).

De acordo com os PPPs das EFAs de Porto Nacional e de Colinas do Tocantins (2015), os instrumentos pedagógicos foram criados e aprimorados conforme a necessidade da EFA e de seus estudantes, depreendendo aspectos importantes da dinâmica de construção do conhecimento da proposta da Pedagogia da Alternância para a educação do campo.

Nesse sentido, nos PPPs das EFAs consta que, para o acompanhamento das atividades dos estudantes, foram pensadas ações a serem realizadas nos espaços de formação escolar e comunitário, nas quais se faz uso de instrumentos didático-pedagógicos organizados em quatro grupos: ações desenvolvidas no espaço escolar, na comunidade, em internato articulado com a comunidade, e organizacionais do processo de ensino e aprendizagem.

No grupo de ações no espaço escolar, com auxílio de professores e monitores, os estudantes fazem a leitura da realidade em que vivem, realizam sessões de estudo com apoio de material didático-científico e experienciam práticas com vistas à realidade do campo. No internato, são utilizados instrumentos didático-pedagógicos como projetos multidisciplinares, viagens de estudo, colocação em comum, acompanhamento personalizado, avaliação da sessão, orientação para aprendizagem, trabalho diário, trabalho prático e disciplinas curriculares.

No tempo-escola são possiveis a recuperação e a valorização de aspectos humanos, além da consolidação de hábitos sociais, da superação do individualismo, bem como da formação partindo de reflexões e análises conjuntas sobre sua própria realidade e a dos demais.

As ações na comunidade são realizadas pelos monitores no tempo sessão-família, com auxílio dos pais, de pesquisas sobre a realidade local e de outros colaboradores existentes no meio. 0 trabalho na família e a vivência na comunidade permitem a consolidação de informações trazidas da escola para a vida e da vida para a escola. Assim, a família vivencia e participa ativamente do processo de formação do sujeito. As ações na comunidade contam com instrumentos didáticos como cursos, estágios, experiências, colaborações, atividades de retorno e visitas às famílias.

As ações no internato com a comunidade estabelecem o elo de ligação entre escola e comunidade. Elas contam com instrumentos didáticos como caderno da realidade, caderno de acompanhamento, plano de estudos, projeto profissional de vida e folha de observação.

As atividades pedagógicas utilizadas necessitam, para sua realização, dos conhecimentos escolares e dos conhecimentos comunitários. É o aprender em diferentes momentos e lugares (trabalho, família, comunidade, escola). Um estudo que parte da experiência, faz a reflexão da realidade e retorna para transformá-la.

As ações organizacionais do processo de ensino e aprendizagem são atividades realizadas pelos monitores, com a participação de estudantes, das famílias, da associação e de outros colaboradores, que contribuem para a organização das outras ações. Ela 
conta com dez instrumentos didáticos (tema gerador, avaliação formativa, formação das famílias, plano de aprendizagem, reunião pedagógica e administrativa, responsável do dia, plano de formação, conselho de classe, contribuição das famílias, coordenação da semana, semana da cultura, datas comemorativas, olimpíadas da EFA, assembleia da associação, jornada pedagógica).

Os instrumentos didático-pedagógicos podem favorecer a participação ativa do estudante, colocando-o na função de sujeito da atividade e, consequentemente, da construção do seu próprio conhecimento. Percebe-se que os instrumentos pedagógicos foram gestados e aperfeiçoados conforme as necessidades e os desafios colocados na perspectiva da implementação da alternância. Segundo Queiroz (2004), as EFAs têm buscado empenho constante em articular a vida do aluno e a escola na dinâmica pedagógica da alternância.

Nessa perspectiva, as EFAs evidenciam, em seus PPPs, metas e ações que possibilitam o processo de formação humana e integral, sobretudo porque a experiência humana se constitui no elemento fundante à construção de novos saberes.

A Formação Integral tem assumido papel cada vez mais central no debate sobre os pressupostos e finalidades da Educação Básica no Brasil. Como concepção de formação e como projeto educacional, ela forma parte da histórica luta pela emancipação humana. Quanto mais integral a formação dos sujeitos, maiores são as possibilidades de criação e transformação da sociedade. (SANTA CATARINA, 2014, p. 25).

Pelo que consta nos PPPs das referidas EFAs, a educação dos jovens do campo está pautada na construção humanística, na valorização dos conhecimentos das famílias e da cultura local, visando ao desenvolvimento da vida e que os sujeitos sejam capazes de se posicionarem diante da realidade social, de modo a construir sua própria história. Trata-se de concepções e princípios da Pedagogia da Alternância que norteiam o processo educativo para a construção do conhecimento, uma vez que valorizam a realidade de vida dos sujeitos, os saberes e a cultura, elementos estes constituintes do processo de formação por alternância.

0 campo tem diferentes sujeitos. São pequenos agricultores, quilombolas, povos indígenas, pescadores, camponeses, assentados, reassentados, ribeirinhos, povos da floresta, caipiras, lavradores, roceiros, sem-terra, agregados, caboclos, meeiros, bóia-fria, e outros grupos mais. Entre estes há os que estão ligados a alguma forma de organização popular, outros não; há ainda as diferenças de gênero, de etnia, de religião, de geração; são diferentes jeitos de produzir e de viver; diferentes modos de olhar o mundo, de conhecer a realidade e de resolver os problemas; diferentes jeitos de fazer a própria resistência no campo; diferentes lutas. (CALDART, 2002, p. 21).

Considerando essa pluralidade de sujeitos, os profissionais da educação do campo precisam criar espaços nos currículos escolares para a construção de diálogo entre os diferentes sujeitos do campo, assim como entre os sujeitos de outros espaços sociais, propiciando a troca de saberes entre esses diferentes grupos. Todavia, nesse diálogo, o respeito às diferenças é crucial ao processo educativo (LIMA, 2010). 


\section{Tecendo considerações}

Ao analisar a trajetória histórica de práticas por alternância no mundo, percebe-se que elas conquistaram espaço e têm se consolidado ainda mais, a partir de instrumentos legais que permitem seu funcionamento. Assim, busca-se afırmar alternativas de organização da educação, principalmente na educação do campo, o que viabiliza um propósito de formação dos sujeitos de forma integral.

Em observância aos objetivos deste estudo, podemos inferir que as EFAs pesquisadas apresentam, em seus Projetos Político-Pedagógicos, objetivos e metas de processos de ensino e aprendizagem a partir de pressupostos da Pedagogia da Alternância, evidenciando perspectivas de formação integral capazes de interferir na vida dos sujeitos que vivem no e do campo.

Pela análise dos Projetos Político-Pedagógicos, pôde-se perceber que as EFAs idealizam a Pedagogia da Alternância considerando os contextos socioculturais dos sujeitos que vivem no e do campo, com vistas a realizar o processo de ensino e aprendizagem na perspectiva da construção dos conhecimentos para a formação integral, coadunando-se com a tipologia de alternância real ou integrativa de que trata Silva (2010).

Para efetivação da Pedagogia da Alternância, as EFAs utilizam-se de instrumentos pedagógicos (plano de estudo, folha de observação, caderno da realidade, o serão de estudo, visitas e viagens de estudo, caderno de acompanhamento) e apresentam em sua estrutura elementos que dão suporte à formação integral dos jovens no movimento da alternância, articulando os tempos e espaços distintos, registrando caminhos da alternância (CAVALCANTE, 2008).

0 presente estudo nos mostra que a Pedagogia da Alternância se constitui numa importante alternativa de atendimento à escolarização dos povos que vivem no e do campo. É um processo em permanente construção e reconstrução. De modo mais objetivo, há que se aprimorar os estudos para que se possa verificar como acontece, na prática, a Pedagogia da Alternância nas EFAs estudadas, de modo a compreender como os estudantes e familiares (re)conhecem essa modalidade educativa.

\section{Referências}

AIRES, Helena Quirino Porto. Um estudo sobre a Pedagogia da Alternância em Escolas Família Agrícola no Estado do Tocantins. 2015. Dissertação (Mestrado em Educação) - Universidade Federal do Tocantins, Palmas, 2015.

ARAÚJJ0, Sandra Regina Magalhães. Escola para o trabalho, escola para a vida: 0 caso da Escola Família Agrícola de Angical - Bahia. 2005. Dissertação (Mestrado em Educação e Contemporaneidade) Universidade do Estado da Bahia, Salvador, 2005.

AZEVEDO, Antúlio José de. A formação de técnicos agropecuários em alternância no Estado de São Paulo: uma proposta educacional inovadora. 1998. Tese (Doutorado) - Universidade Estadual Paulista Júlio de Mesquita Filho, Marília, 1998. 
BRASIL. Lei n. 9.394, de 20 de dezembro de 1996. Estabelece as diretrizes e bases da educação nacional. Diário Oficial da União, Brasília, DF, 23 dez. 1996.

CALDART, Roseli Salete. Por uma educação do campo: traços de uma identidade em construção. In: KOLLING, Edgar Jorge; CERIOLI, Paulo Ricardo; CALDART, Roseli Salete (Org.). Por uma educação do campo: identidade e políticas públicas. Brasília, DF: Articulação Nacional Por Uma Educação do Campo, 2002. p. 18-25. (Por uma educação no campo; n. 4).

CALDART, Roseli Salete et al. Dicionário da educação do campo. Rio de Janeiro: Expressão Popular, 2010.

CAVALCANTE, Nilton Vale. A pedagogia da alternância na visão dos egressos da EFA de Porto Nacional - T0: a possibilidade de uma formação integral. 2008. Dissertação (Mestrado) - Universidade Federal do Pará, Belém, 2008.

COLINAS DO TOCANTINS. Escola Municipal Família Agrícola "Zé de Deus". Projeto político-pedagógico. Colinas do Tocantins: [s. n.], 2015.

CONCAGH, Viviana Bosi. A Escola Família Agrícola no Espírito Santo. Cadernos de Pesquisa, São Paulo, n. 68, p. 89-98, fev. 1989.

GIMONET, Jean-Claude. Alterance et relations humaines. Paris: Messonance: Unmfreo, 1983.

GIMONET, Jean Claude. L'alternance en formation "méthode pédagogique au nouveau système éducatif? L'experience des maisons familiales rurales. In: DEMOL, Jean-Noël; PILON, Jean-Marc. Alternance, dévelopment personnel et local. Paris: Harmattan, 1998. p. 51-66.

GIMONET, Jean-Claude. Nascimento e desenvolvimento de um movimento educativo: as Casas Familiares Rurais de Educação e orientação. In: SEMINÁRIO INTERNACIONAL DA PEDAGOGIA DA ALTERNÂNCIA: Alternância e Desenvolvimento, 1., 1999, Salvador. Anais... Salvador: Unefab, 1999. p. 39-48.

GIMONET, Jean-Claude. Praticar e compreender a pedagogia da alternância dos CEFFAs. Petrópolis: Vozes, 2007.

LIMA, Elmo de Souza. Multiculturalismo, currículo e formação docente: construindo diálogos entre as diversidades no contexto das práticas educativas. Linguagem, Educação e Sociedade, Teresina, p. 15-31, 2010.

NASCIMENTO, Claudemiro Godoy do. Educação do Campo Escola Família Agrícola de Goiás: 0 caminhar da teimosia de um movimento social educativo. Revista Diálogo Educacional, Curitiba, v. 4, n. 8, p. 79-95, jan./abr. 2003.

NASCIMENTO, Claudemiro Godoy do. Pedagogia da resistência: alternativa de educação para o meio rural. Gurapari: Ex Libris, 2007.

NOSELLA, Paolo. Educação no campo: origens da pedagogia da alternância no Brasil. Vitória: Edufes, 2014.

PORTO NACIONAL. Escola Família Agrícola. Projeto político-pedagógico. Porto Nacional: [s. n.], 2015. QUEIROZ, João Batista Pereira de. Construção das Escolas Família Agrícolas no Brasil: ensino médio e educação profissional. 2004. Tese (Doutorado) - Universidade de Brasília, Brasília, DF, 2004. 
QUEIROZ, João Batista Pereira de. 0 processo de implantação da Escola Família Agrícola (EFA) de Goiás. 1997. Dissertação (Mestrado em Educação) - Universidade Federal de Goiás, Goiânia, 1997.

SANTA CATARINA. Governo do Estado. Proposta curricular de Santa Catarina: formação integral na educação básica. Florianópolis: [s. n.], 2014.

SILVA, Lourdes Helena da. A relação escola-família no universo das experiências brasileiras de formação em alternância. 2000. Tese (Doutorado) - Pontifícia Universidade Católica de São Paulo, São Paulo, 2000.

SILVA, Lourdes Helena da. As experiências de formação de jovens do campo: alternância ou alternâncias? Viçosa: UFV, 2003.

SILVA, Lourdes Helena da. As experiências de formação de jovens do campo: alternância ou alternâncias? Viçosa: UFV, 2012.

SILVA, Lourdes Helena da. Concepções e práticas de alternâncias na educação do campo: dilemas e perspectivas. Nuances, Presidente Prudente, v, 17, n. 18, p. 189-192, jun./dez. 2010.

TEIXEIRA, Edival Sebastião; BERNATT, Maria de Lourdes; TRINDADE, Glademir Alves. Estudos sobre pedagogia da alternância no Brasil: revisão de literatura e perspectivas para a pesquisa. Educação e Pesquisa, São Paulo, v. 34, n. 2, p. 227-242, maio/ago. 2008.

Recebido em: 21.07.2016

Revisões em: 08.03.2017 Aprovado em: 23.05.2017

Idemar Vizolli é doutor em educação matemática pela Universidade Federal do Paraná (UFPR) e professor adjunto na Universidade Federal do Tocantins (UFT - campus de Arraias).

Helena Quirino Porto Aires é mestra em educação pela Universidade Federal do Tocantins (UFT - campus de Arraias), professora da mesma instituição e integrante do Grupo de Estudos e Pesquisas em Educação do Campo (Gepec/UFT).

Mylena Gonçalves Barreto é acadêmica de pedagogia pela Universidade Federal do Tocantins (UFT - campus de Arraias). 